\title{
AN OPEN PROBLEM IN FLOW OF FLUIDS ANTONIO VALIENTE BARDERAS, LUCILA MÉNDEZ CHÁVEZ
}

\author{
Facultad de Química, UNAM, C.U ${ }^{1}$ \\ ${ }^{1}$ Internal circuit s/n Edif. Department of chemical engineering, University City, Mexico D.F. 04510
}

\begin{abstract}
Experimental teaching is very important in education of engineering'students. This activity promotes the interactivity and the participation of the students, propitiating that they acquire knowledge, skills, habits and attitudes. In this work we present an open problem of flow of fluids that is solved by experimentation, to help the students achieve meaningful learning in this subject.
\end{abstract}

Keywords: Empirical models, flow of fluids, problem solving, experimentation.

\section{INTRODUCTION}

If it is accepted that the scientific method is the maximum achievement that has made possible the modern science, and that in certain cases it is applicable in some problems of everyday life, then it is desirable that the student knows, both by streamlining which implies its use as to extend advances in science (Estany, 2007).

The experimental method is mainly applied in the so-called natural sciences and is based on the observation of phenomena and experiments. In the experimental method, given a series of observations, we can built a model or hypothesis, which is analyzed to find its consequences, and then we can make predictions that can be verified by means of experiments (Rivero, 1982).

The application of the method begins with posing a problem whose solution is of interest. Then, applying previous knowledge, we can formulate a hypothesis that aims to identify the most important variables involved in the given phenomenon and a through a deductive process is it possible to make a prediction about the relationship between the relevant variables in the problem and the mathematical relationship between them (Gutierrez, 1986). This is the forecast model. If this last part is not feasible, at least it will be clear which variables may be joined by an empirical relationship whose exact form will then be sought.

Knowing that measure, we can plan and execute an experiment allowing to verify the prediction made, or, where appropriate, find the wanted empirical relationship. For this purpose it is necessary that the experimental values have the level of precision required.

The next step is to analyze the data obtained from the experiment, interpret the results of this analysis and to draw the conclusions about the validity of the assumptions made, the quality of the experiment, etc. Once this is done, it will be possible to decide if the issue raised initially has been resolved, and in which measure the initial assumptions are appropriate to describe the observed phenomenon. In this case, we can even reach the conclusion that the problem planted at the beginning does not make sense, and which must then be restated. It is also common that the initial hypothesis be amended to introduce factors that were not included and whose influence is suspected, it may be important (Pérez, 2003). Finally, where the problem is considered to be satisfactorily resolved, it is necessary to write a report that communicate the results in a clear way.

Experimental teaching is of utmost importance for the student

What is known relates (previous knowledge) with the new learning (new information) to deepen, linkages, reflecting on the new learned and apply it to new situations. Another important role of the experimental work is that it promotes interactivity and participation of the students, providing that they acquire not only knowledge, but skills, habits and attitudes.

As researchers like: (Tamir and Garcia, 1992), (Hofstein and Lunetta ,1982), have stated "laboratories has strong potential because the student develops and tests hypothesis and can plan and carry out experiments"; because the laboratories facilitate the understanding of concepts that sometimes are very abstract; because they offer to the students the opportunity to develop important skills such as handling of instruments and equipment, the organization of teamworks as well as the communication of the data and the conclusions to which they arrive. Experimental work also promotes the acquisition of skills for solving problems through action; in other words, to learn to do.

In conclusion, experimental work allows the student to learn to observe the phenomena, to identify the most important variables involved in the given phenomenon through the application of prior knowledge and a deductive process learn how to make a prediction about the relationship that they can save the relevant variables in a process. 


\section{IMPORTANCE OF PROBLEM SOLVING AND THE EXPERIMENTAL ACTIVITIES IN CHEMICAL ENGINEERING}

Chemical engineering has to do with the application and generation of knowledge to create, enhance, optimize, or innovate processes in a sustainable environment, and above all, to make them effective and efficient; this is accomplished, largely, with problem solving supported by the corresponding scientific basis.

Researchers as (Gil, Torregrosa Martínez and Ramirez 1992), among others, propose as a strategy for teaching to solve open problems that require qualitative and quantitative analysis of a situation. But this proposal part of the consideration of unlock the usual solving teaching problems and its limitations within the framework of a work mechanical, and abstract, devoid of meaning that usually have the classroom problems. This kind of problems contribute very little to a meaningful learning because the solution of the problem is done linearly, "clearly". The students learn the solution and repeat it in identical situations, but do not learn to deal with a real problem and any small change implies insurmountable difficulties causing the abandonment and the simple copy. In summary, point out: "the problems, instead of being a privileged occasion to build and deepen the knowledge, become a reinforcement of conceptual and methodological errors".

The researchers say that another problematic aspect is the inclusion of data in the statement of the problems. Thus, in order to solve a problem, the students search those equations that have a relationship with the data.

The researchers think that problems with data simplifies the solution These researchers pose other questions: ambiguity, or open situations, are not an essential feature of the genuinely problematic situations? And is it not also one of the fundamental tasks of the scientific work to define the open problems and impose simplify conditions? Does not scientific knowledge required of a work of investigation?

Joseph Schwab (1969) began to apply the term inquiry to science education when he noted that the scientific knowledge is changing rapidly. Schwab argued against teaching scientific facts, and instead proposed that teachers should involve students with problems that motivated them to learn about natural phenomena by means of inquiry, at the same time, learn something about the strengths and weaknesses of the processes of scientific inquiry. He developed a scheme to describe the degree of inquiry (inquiry approach) in a Biology lab. At the highest level of inquiry the student confronts the phenomenon directly, without a guide. And at the other end of the spectrum of experiences whit low levels of inquiry or none when a problem with experimentation is proposed, he shows the methodology to be followed to find the solution. Herron in 1971 subsequently perfected the scale that now is still used (Singer and Hilton, 2005).
Table 1 level of investigation of practical work proposed by Schwab and Herron (Singer et al, 2005).

\begin{tabular}{|l|l|l|l|}
\hline LEVEL & PROBLEM & DEVELOPMENT & RESPONSE \\
\hline 0 & Defined & Defined & Defined \\
\hline 1 & Defined & Defined & Open \\
\hline 2 & Defined & Open & Open \\
\hline 3 & Open & Open & Open \\
\hline
\end{tabular}

Thus, for example, an experimental activity of level 0 contains a question posed, a method to resolve it and a response to it. In level 1 the question and the method are provided and students should look for the result. At level 2 the question arises and the student must find the method and response. And as you can be seen in the level 3 no element is provided.

Intuitive thinking leads initially to inquiry and the construction of hypotheses as a key aspect of the scientific work and the solution of a problem. It is to enable you to deal with unfamiliar situations that require initial attempts.(Gil and col, 1992)

\section{FLOW OF FLUIDS IN THE LABORATORY OF CHEMICAL ENGINEERING}

The students of Chemical Engineering at the Faculty of Chemistry in the Universidad Nacional Autónoma de México (UNAM) take several laboratories of Unit Operations. An average of 100 students of the sixth ,seven and eight semester take this courses in the Unit Operations laboratory. In this laboratory have been built, deliberate, appliances and equipment in which experiments that clarify the concepts stated in theoretical classes can be made. Unlike a traditional education where is attributed to the experiment the function of confirm or refute hypotheses, concepts, principles, etc., in this laboratory, from about 10 years ago, it has been thought that it is important that students develop through experimentation, models representing different phenomena of the subject. Currently, in some experiments, the teacher posses a problem, that will require to develop a mathematical model for the phenomena under study. The professor provides a script that contains the experimental development and a series of questions that guide the students to the solution of the problem.

We are working on a new proposal in which, for a typical session, any experimental procedure or guide are provided for the mathematical model. We only orient the students on how to handle the equipment available and the security measures that should be taken. We think that this information is sufficient for students to: a) identify the variables involved, b) propose the measurements to be carried out, c) carry out measurements, d) analyze and transform results e) to represent their results in other formats, such as tables or charts, f) interpret these representations, and f) to carry out a mathematical analysis to establish the relationships between two or more variables involved in the phenomena under study. 


\section{PROPOSED EXPERIMENTAL WORK}

We propose an experiment to show that there is a relationship between the variables that involve the flow of fluid inside a pipe.

One of the fundamental problems in the science of fluids is to find the key variables involved in the calculation of flows that can travel through a pipe. The engineering design parameters, often depend on many independent variables. Frequently, this functional dependence is best characterized with multivariable equations of power.

In the laboratory of chemical engineering of our Faculty, we have a system like the one shown in the following figure, in which the students can carry out different experiments.

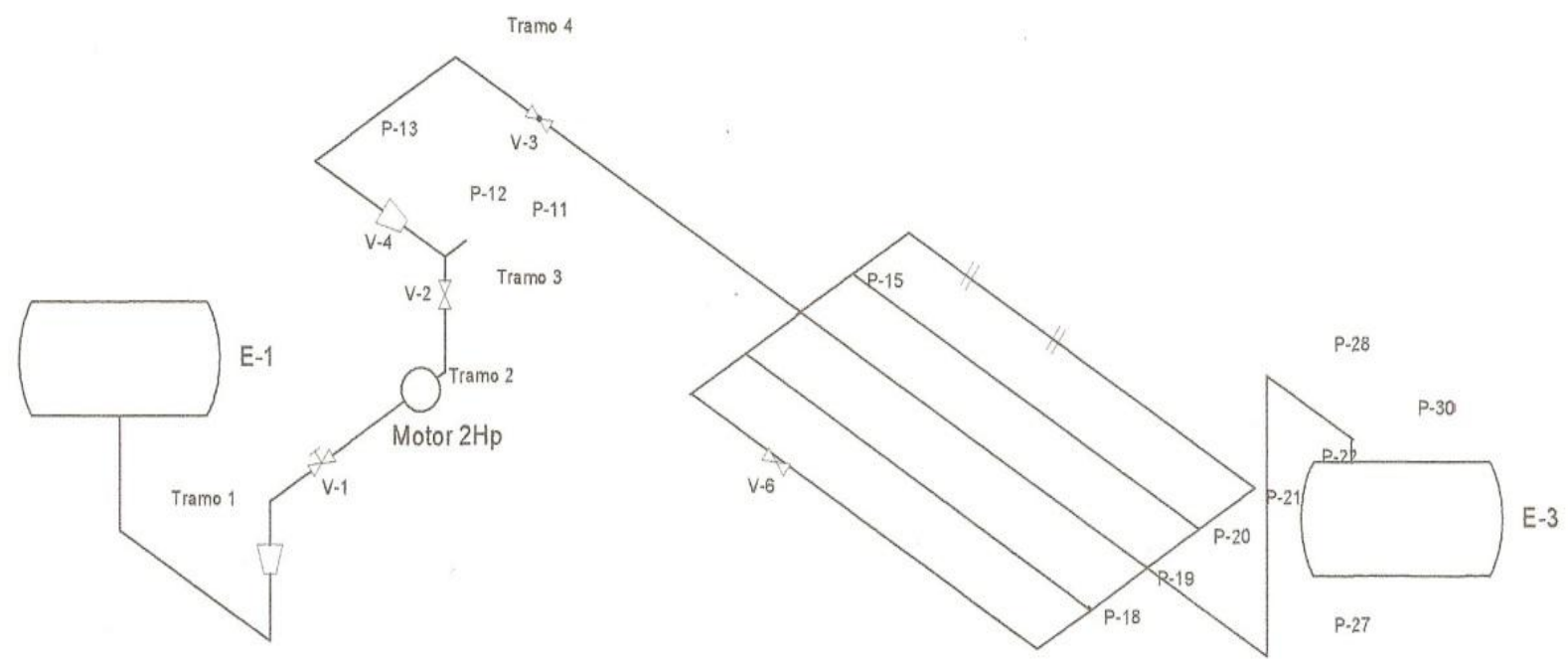

Fig 1

In such a system, in which circulates water, the variables that can be managed are: the diameters of the pipe, the height of liquid in the tanks and therefore the flow of fluid that travels through the pipes.

\section{EXPECTED RESULTS}

The relationship between these variables could be put as an empirical equation in potential form. The equation of powers that could explain the flow would be:

$$
C a=a_{o} D^{a_{1}} S^{a_{2}}
$$

Where $\mathrm{Ca}$ is the flow rate or volumetric flow (in cubic metres per second),

$\mathrm{S}$ is the slope (in meters),

$\mathrm{D}$ is the diameter of the tube (in meters/ meter)

and $\mathrm{a}_{0}, \mathrm{a}_{1}$, and $\mathrm{a}_{2}$ are coefficients.

In order to find the relationship between those variables the students could carry out a series of experiments such as those displayed in the table below:
Table 2

\begin{tabular}{|l|l|l|l|}
\hline Experiment & $\begin{array}{l}\text { Diameter in } \\
\mathrm{m}\end{array}$ & $\begin{array}{l}\text { Slope } \\
\mathrm{m} / \mathrm{m}\end{array}$ & $\begin{array}{l}\text { Flow rate in } \\
\mathrm{m} 3 / \mathrm{s}\end{array}$ \\
\hline 1 & 0.305 & 0.001 & 0.039722 \\
\hline 2 & 0.61 & 0.001 & 0.235493 \\
\hline 3 & 0.915 & 0.001 & 0.686618 \\
\hline 4 & 0.305 & 0.01 & 0.133351 \\
\hline 5 & 0.610 & 0.01 & 0.819969 \\
\hline 6 & 0.915 & 0.01 & 2.3833 \\
\hline 7 & 0.305 & 0.05 & 0.314936 \\
\hline 8 & 0.610 & 0.05 & 1.929338 \\
\hline 9 & 0.915 & 0.05 & 5.674525 \\
\hline
\end{tabular}

\section{Calculations}

A multiple linear regression of data transformed using logarithms provides a means to evaluate such relationships Extracting logarithms to equation (1) we have:

$$
\ln C a=\ln a_{0}+a_{1} \ln D+a_{2} \ln S
$$

Using the logarithms of the experimental data we generate the table 3 : 
Table 3

\begin{tabular}{|l|l|l|}
\hline $\log \mathrm{Ca}$ & $\log \mathrm{D}$ & $\operatorname{logS}$ \\
\hline-3.225858 & -1.187444 & -6.907755 \\
\hline-1.446075 & -0.494296 & -6.907755 \\
\hline-0.3759783 & -0.088831 & -6.907755 \\
\hline-2.014768 & -1.187444 & -4.60517 \\
\hline-0.198489 & -0.494296 & -4.60517 \\
\hline 0.868486 & -0.088831 & -4.60517 \\
\hline-1.155385 & -1.187444 & -2.995732 \\
\hline 0.6571778 & -0.494296 & -2.995732 \\
\hline 1.7359879 & -0.088831 & -2.995732 \\
\hline
\end{tabular}

Applying the data from table 3 to equation (2) gives the following list of equations:

Table 4

\begin{tabular}{|l|}
\hline$-3.225858=\ln \mathrm{a}_{0}-1.187444_{1}-6.907755_{2}$ \\
\hline$-1.446075=\ln \mathrm{a}_{0}-0.494296_{1}-6.907755_{2}$ \\
\hline$-0.3759783=\ln \mathrm{a}_{0}-0.088831_{1}-6.907755_{2}$ \\
\hline$-2.014768=\ln \mathrm{a}_{0}-1.187444_{1}-4.60517_{2}$ \\
\hline$-0.198489=\ln \mathrm{a}_{0}-0.494296_{1}-4.60517_{2}$ \\
\hline $0.868486=\ln \mathrm{a}_{0}-0.088831_{1}-4.60517_{2}$ \\
\hline$-1.155385=\ln \mathrm{a}_{0}-1.187444_{1}-2.995732_{2}$ \\
\hline $0.6571778=\ln \mathrm{a}_{0}-0.494296_{1}-2.995732_{2}$ \\
\hline $1.7359879=\ln \mathrm{a}_{0}-0.088831_{1}-2.995732_{2}$ \\
\hline
\end{tabular}

This system can be solved by Gaussian elimination to get: $\ln a_{0}=3.6 ; a_{1}=2.64 ; a_{2}=0.54$, therefore $\mathrm{a}_{\mathrm{o}}=$ 36.6

And then

$$
\mathrm{CA}=36.6 \mathrm{D}^{2.64} \mathrm{~S}^{0.54}
$$

This empirical equation can be used to predict the flow of water through the pipes giving a slope and a diameter...

Example:

If $\mathrm{D}=0.305 \mathrm{~m}$, and $\mathrm{S}=0.01 \mathrm{~m} / \mathrm{m}$

Then

$$
C a=36.6(0.305)^{2.64}(0.01)^{0.54}=0.1324 \frac{m^{3}}{s}
$$

It should be noted also that the equation can be used for other purposes in addition to calculate volumetric flow. For example, the slope can be based on friction loss $\frac{\sum F}{M}$ and the length of the $\mathrm{L}$ pipe.

$$
S=\frac{\frac{\sum F}{M}}{L}
$$

If this relation is substituted in (3) and solve for $S$ we obtained that:

$$
\frac{\sum F}{M}=\frac{L}{780.6} C a^{1.85} D^{-4.888}
$$

This relationship is called in hydraulics the equation of Hazen-Williams (Valiente, 1998), this equation is presented in theory .

But we believe that if the student performs experiments and deducts it . It will have more meaning that the operative solution of applying the Hazen-Williams equation.

While the problems the students solve do not have the complexity of those who will later face in their professional lives, we believe that careful analysis of a complex problem leads them to separate this into a set of simple problems. That is, we are encouraging the ability to problem-solving that is the basis of their professional training.

\section{CONCLUSION}

The function of confirm or refute hypotheses is traditionally attributed to the experiment. When a scientist enters in a laboratory already have many models in his head, that does not necessarily determine, but allow him to direct and understand his actions. The situation may be different with the students, because them have or does not have any model in the head. The consequence is that for a scientist or a student is essential to go to the labs and see what actually happens in them, only thus can capture what is an experiment, their scope and limitations. According to David Ausubel (1983), meaningful learning is accomplish when the study material is potentially significant. Well selected experiments comply with this objective because they provide the basis to bring new significant information for the student.

\section{REFERENCES}

AUSUBEL, NOVAK, HANESIAN (1983). Psicología Educativa: Un punto de vista cognoscitivo. $2^{\mathrm{a}}$. Ed. Trillas . México

ESTANY, A. (2007). Innovación tecnológica y tradiciones experimentales Revista Ciencia -octubre - diciembre .Pág. 34

[3] GIL-PÉREZ, D., MARTINEZ TORREGROSA, J. y SENENT, F. (1988). El fracaso en la resolución de problemas: una investigación orientada por nuevos supuestos. Enseñanza de las Ciencias, 6 (2), 131146.

[4] GIL-PÉREZ, D., MARTINEZ TORREGROSA, J. y RAMIREZ, L. (1992). La didáctica de la resolución de problemas en cuestión: Elaboración de un 
modelo alternativo. Didáctica de las Ciencias Experimentales y Sociales, 6, 73-85.

[5] GUTIÉRREZ, C. (1986). ARANZETAIntroducción a la metodología experimental. México: Limusa.

[6] HOFSTEIN, A. y LUNETTA, V.N. (1982). The role of laboratory in science education part II. The Science School Review, 52, pp. 201-217.

[7] PÉREZ, F. (2003) La enseñanza experimental México: Facultad de Ingeniería, UNAM

[8] RIVERO, H y ROSAS L. (1982). El método científico aplicado a las ciencias experimentales. México: Trillas.

[9] SCHWAB, JOSEPH. (1969), College Currículum and Student Protest. Chicago. University of Chicago Press.

[10] TAMIR, P. y GARCÍA ROVIRA, M. (1992). Características de los ejercicios de prácticas de laboratorio incluidos en los libros de texto de ciencias utilizados en Cataluña. Enseñanza de las Ciencias, 10(1), pp. 3-12.

[11] SINGER, S. Y HILTON, M. (2005). America's lab report: Investigations in high school science. Washington: National Academy Press., Schweingruber Editores

[12] VALIENTE, A. (1998). Problemas de flujo de fluidos. México: Limusa. 